\title{
Overgrowth Syndrome and Multi-Stage Reconstruction of Hand and Feet Deformations
}

\author{
Erik Vrabič, ${ }^{1 *}$ Maja Skerbinjek Kavalar, ${ }^{2}$ Milojka Molan Štiglic, ${ }^{3}$ Slavko Kramberger ${ }^{4}$ \\ ${ }^{1}$ Esthetic and General Surgery, University Medical Center Maribor, Slovenia \\ ${ }^{2}$ Consultant Pediatrician, University Medical Center Maribor, Slovenia \\ ${ }^{3}$ Pediatrician, University Medical Center Maribor, Slovenia \\ ${ }^{4}$ Consultant Orthopedic Surgeon, University Medical Center Maribor, Slovenia
}

\begin{abstract}
A case of asymmetric overgrowth of feet, fingers and toes is presented and the performed diagnostic and multi-stage surgical reconstruction described. The condition in hands and feet was already present at birth. The hypertrophic growth advanced progressively, and histological investigation of the affected tissues revealed no pathology. The examination of inner organs, skin, subcutaneous tissue, nerves and vessels showed no deviations, the girl's karyotype was normal, $46 \mathrm{xx}$, no mosaicism was confirmed.
\end{abstract}

In view of the new diagnostic criteria, this case cannot be assigned to any of the overgrowth syndromes. The most suitable classification would be in the group of Proteus-like syndrome. At this time only isolated hypertrophy of soft tissues and skeleton is present. According to the data from the literature, later development of anomalies is possible, so Proteus-like syndrome cannot be completely excluded.

Keywords: Overgrowth, Hands and feet, Multi-stage reconstruction, Child

\section{Introduction}

Overgrowth syndrome presents as an etiologically very heterogeneous but as yet not clearly defined set of symptoms. An accurate and adequate diagnosis is crucial for further research and clinical care of patients. The syndrome can occur as an isolated phenomenon, in certain tissues or as part of the syndromes related to overgrowth. The latter include Proteus Syndrome (PS), Proteus-like Syndrome (PLS), Klippel Trenaunay Syndrome (KTS), hemihyperplasia with lipamatosis (HHML). ${ }^{1}$ The most common cause of overgrowth in tissues is disorder in the differentiation of one or more cell types. The maturation, development and function of the cells may also be disrupted. While only skeletal or soft tissue cells may be affected, the syndromes are usually intertwined. The etiol ogy and mechanisms of overgrowth syndrome have not yet been adequately explained. Historically, localized malformations were referred to as harmatomata (Greek: hamaria - sin), gigantism and macrodistrophia. ${ }^{2}$ The PTEN mutation (Phosphatase and TENsin homologue deleted on chromosome) on germline cells constitutes a predisposition for variable phenotypic disorders and masking of variable clinical symptoms. These include PS, PLS, Cowden Syndrome, Bannayan-Riley-Ruvalcaba Syndrome, and the haramtomata tumor syndrome known as PTEN (PHTS). Variable genetic mutations of the PTEN and related genes are manifested as variable clinical symptoms ${ }^{3,4}$. According to diagnostic criteria, it is best to classify them as PLS.

\footnotetext{
Quick Response Code:

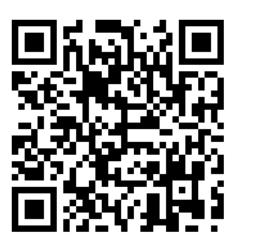

*Corresponding author: Erik Vrabič, Consultant in Plastic, Reconstructive, Esthetic and General Surgery, University Medical Center Maribor, Ljubljanska 5, 2000 Maribor, Slovenia

Received: 10 December, 2020

Published: 17 December, 2020

Citation: Erik V, Maja SK, Milojka MŠ, Slavko K. Overgrowth Syndrome and Multi-Stage Reconstruction of Hand and Feet Deformations. Mod Res Plast Recon Sur. 2020;1(1):1-6. DOI: 10.53902/MRPRS.2020.01.000501
} 
Multi-stage surgical reconstruction halted the overgrowth, thus improving the function of the affected parts of the limbs. As a consequence, near normal function has contributed to a higher quality of life.

\section{The Presentation of the Case}

A 22 year-old female has been monitored and treated since birth for changes indicative of PS. She was the third pregnancy of a 34 year-old mother. The first pregnancy was terminated (abortion), while her four year older brother is healthy. There are no chronic diseases or hereditary malformations in the family. This pregnancy was categorised as risky due to cervical weakness. The delivery was normal in the $41^{\text {st }}$ gestation week, Apgar 9.9. Immediately after birth, an anomaly in the distal phalanges of both baby's feet and in the second finger of her left hand was noticed. In order to check for other potential malformations an ultrasound scan of her brain and abdomen was performed, but showed no evidence of other pathology. The feet were in calcaneovalgus position with limited plantar flexion. We noticed hypetrophy of soft tissues and of distal phalanges in both feet, 1-2 fingers of the right hand, 2-3 toes of the left foot and hypertrophy of index fingers in both hands. The radiograph of the feet showed that the metatarsal bones were shorter and showed thickening. Medial and distal phalanges of all other digits were also showed thickening. Due to the hypertrophy of the soft tissues, the distances between them were larger than normal. Only talus and calcenaus were developed in the ossification center, but no cuboid center. The radiograph of the left wrist showed normally developed carpal bones, which were set widely apart due to the ovegrowth of soft tissues. The bone substance of both feet and hands was normal. The ultrasound of blood vessels in the feet showed no presence of AV fistula. The peripheral blood test confirmed a normal female 46 , xx karyotype without chormosome alterations.

Somatic and psychomotor development of the child was normal, with her weight and height above the $90^{\text {th }}$ percentile. A medical consillium consisting of a pediatric endocrinologist, orthopedic surgeon, cytongentic specialist and plastic surgeon agreed on a diagnosis of suspected PLS.

At the age of 2, the radiograph showed hyperplasia of the I, II and III. metatarsus and associated phalanges in both feet (Figure 1). At the age of 2 and a half, hyperplasia manifested itself in all the bones of the right and left hand, as well as in the left index and middle fingers and associated metacarpals. There were also indications of the hyperplasia of metacarpal bones and phalanges of the index and middle finger in the right hand (Figure 2). Clinically, the affected parts of the limbs also showed hypertrophy of sub cutis (Figure 3). The girl's gait was becoming affected, leading to the wearing of orthopedic shoes at all times. Her development was closely monitored by the pediatrician, plastic surgeon and orthopedic surgeon. Ultrasound scans of the abdomen in the period up to 2009 showed only a slightly less developed uterus and small cysts on both ovaries. In February of 2010, a larger and fast growing cyst on her right ovary occurred, which we removed surgically. Histological analysis showed no malign growth. In June of 2015 , we performed a subtrochanteric ostetomy to shorten her right lower limb.

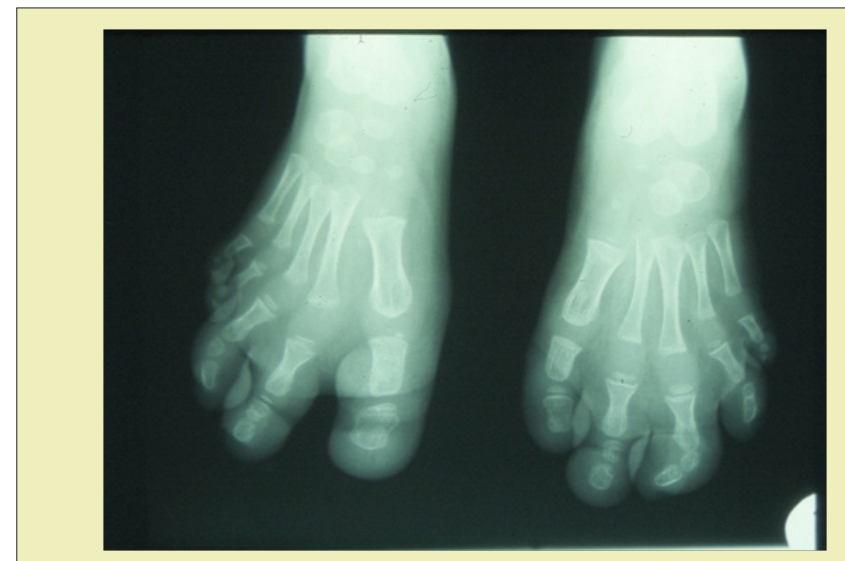

Figure 1: Hyperplasia of three medial metatarsals and of all related phalanges in both feet. Angulations of phalanges in the $1^{\text {st }}$ left toe and the $3^{\text {rd }}$ toe of both feet.

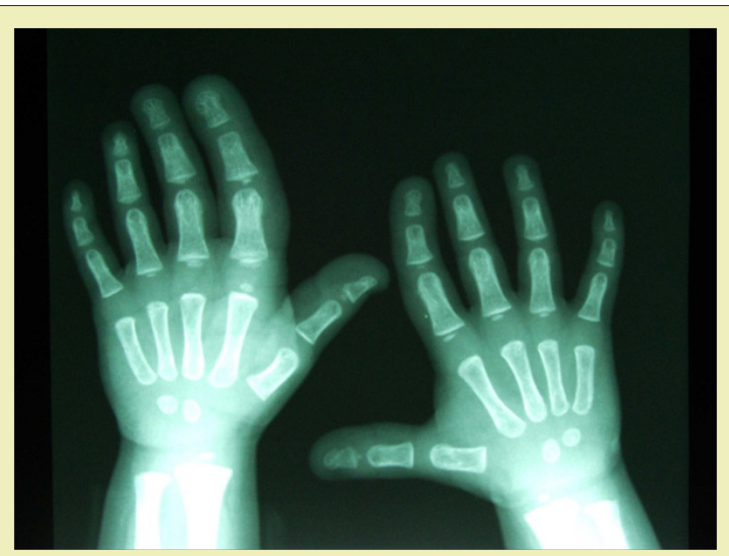

Figure 2: Hyperplasia of three radial metacarpals and related phalanges in both hands. Moderate ulnar deviation in both index fingers and the middle finger of left hand.

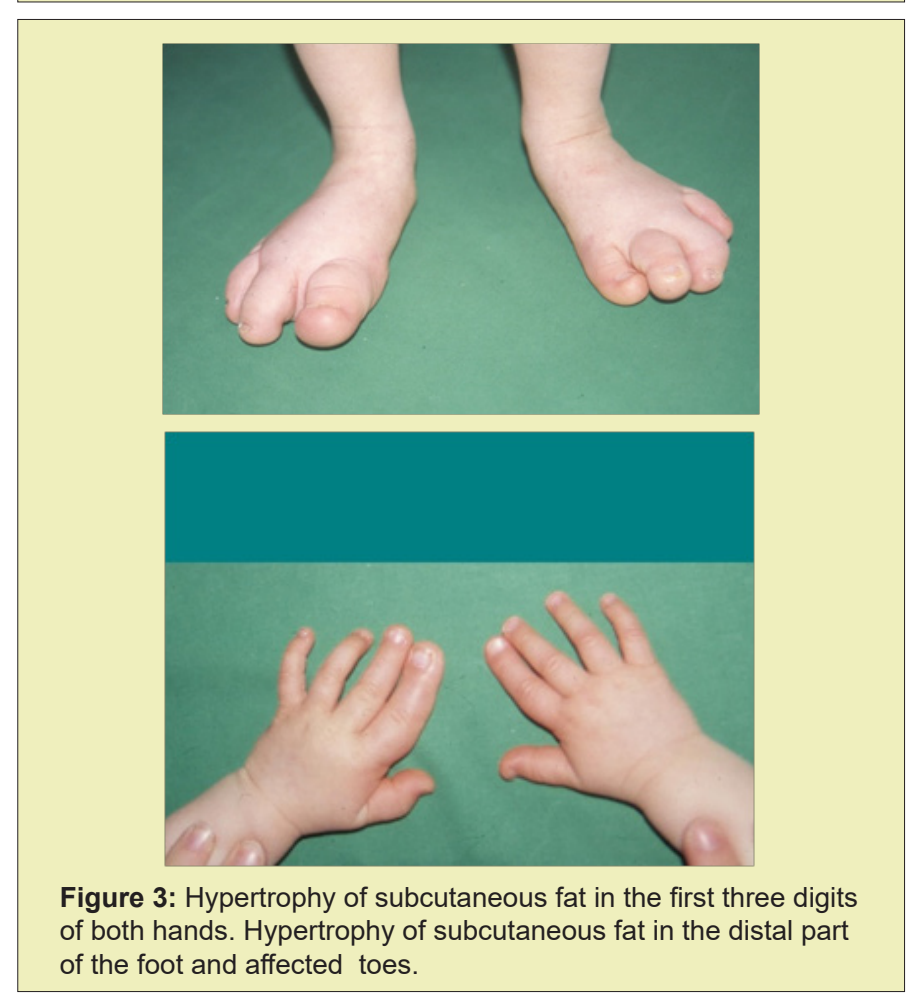


Doppler ultrasound scans of the lower limbs confirmed small $\mathrm{AV}$ connections in the feet. Electrocardiography and a follow-up examination two years later showed a normal heart structure except for intraventricular septum, the thickness of which was at the upper limit of normal. ECG scans were normal for the patient's age. ORL and occulist examinations showed no anomalies. EEG results were also consistently normal. At the age of 6 , the radiograph showed that the child's bones were aging disproportianately quickly by two years. Her family was offered a consultation by a clinical phsychologist, who evaluated the child's pscychological abilities and from then on monitored her development.

\section{Surgical Reconstruction}

Macrodactyly of hands and feet is a frequent clinical sign of PS and PLS. It is a problem from both a functional and esthetic perspective ${ }^{2}$.

Correction was performed in several stages including epiphisiodesis, wedge and vertical ostetomies, osteosynthesis of metatarsal bones and of phalanges, the amputation of toes and related metatarsals, and the reduction of soft tissues.

The child was first examined by the plastic surgeon at the University Medical Center Maribor in September 1998, when she was 9 months old. We recommended a well- planned multi-stage reconstruction depending on the localized progression of deformations and body growth. When she was two years old, she underwent a genetic consultation at the Aschau Orthopedic Clinic in Munich. The Munich team also consulted the NIH genetics in the USA. They all agreed with our reconstruction plan.

The first surgery was performed at the age of 3 and included epiphisiodesis of the phalanx of the left index finger, correction of the ulnar deviation of the finger and reduction of subcutaneous tissue on the ulnar side of the finger. A portion of the hypertrophic tissue of the digital nerve and of the subcutaneous tissue was sent for histological examination, which showed non-specific results.

The second surgery a year later involved a secondary reduction of subcutaneous tissue in the $1^{\text {st }}$ and $3^{\text {rd }}$ fingers of the left hand, additional correction of the ulnar deviation of the $2^{\text {nd }}$ and $3^{\text {rd }}$ fingers with wedge resection of the middle phalanx. We thus managed to stop the overgrowth of the left-hand fingers.

At the ages of 4 and 5 , we focused on the feet. We first performed the epiphisiodesis of the $1^{\text {st }}, 2^{\text {nd }}$ and $3^{\text {rd }}$ metatarsal bones in the right foot, shortening the $1^{\text {st }}$ metatarsal by $2 \mathrm{~cm}$, the $2^{\text {nd }}$ by $3.5 \mathrm{~cm}$ and the $3^{\text {rd }}$ by $1.5 \mathrm{~cm}$. At the same time, we performed the epiphisiodesis of proximal phalanges of the $1^{\text {st }}, 2^{\text {nd }}$ and $3^{\text {rd }}$ toes as well as the reduction of the subcutaneous tissue of the toes and related metatarsals.

The fourth surgery focused on the correction of the left foot. We decided on the amputation of the $3^{\text {rd }}$ toe and related metatarsal, since the corrections of the right side of the foot failed to sufficiently reduce its width. Furthermore, we performed an epiphisiodesis, shortening the $2^{\text {nd }}$ metatarsal by $1.5 \mathrm{~cm}$ and the proximal phalanx of the $1^{\text {st }}$ toe by $1.2 \mathrm{~cm}$, as well as the reduction of subcutaneous tissue on the plantar side of the foot.
After rehabilitation, the results in the left foot were both functionally and esthetically better than in the right foot, which is why we decided on amputation on the right foot as well. In October 2005 we perfomed the amputaion of the $2^{\text {nd }}$ toe and related matatarsal in the right foot. We also reduced subcutaneous tissue.

The sixth surgery in 2006 involved additional correction of the ulnar deviation of the right thumb. At age 10 and a half, in September 2008, we performed a liposuction of the hypertrophic fat tissue of the distal half of the foot. We removed $100 \mathrm{ml}$ of fat and, in addition, excised the hypertrophic subcutaneous tissue in the $1^{\text {st }}$ toe.

From 2005 on, we observed a discrepancy in the length of the patient's lower limbs. At first we managed to correct the discrepancy with orthopedic shoes. After the initial and relatively rapidly occurring discrepancy of limb length, this settled after a few years (Figure 4).

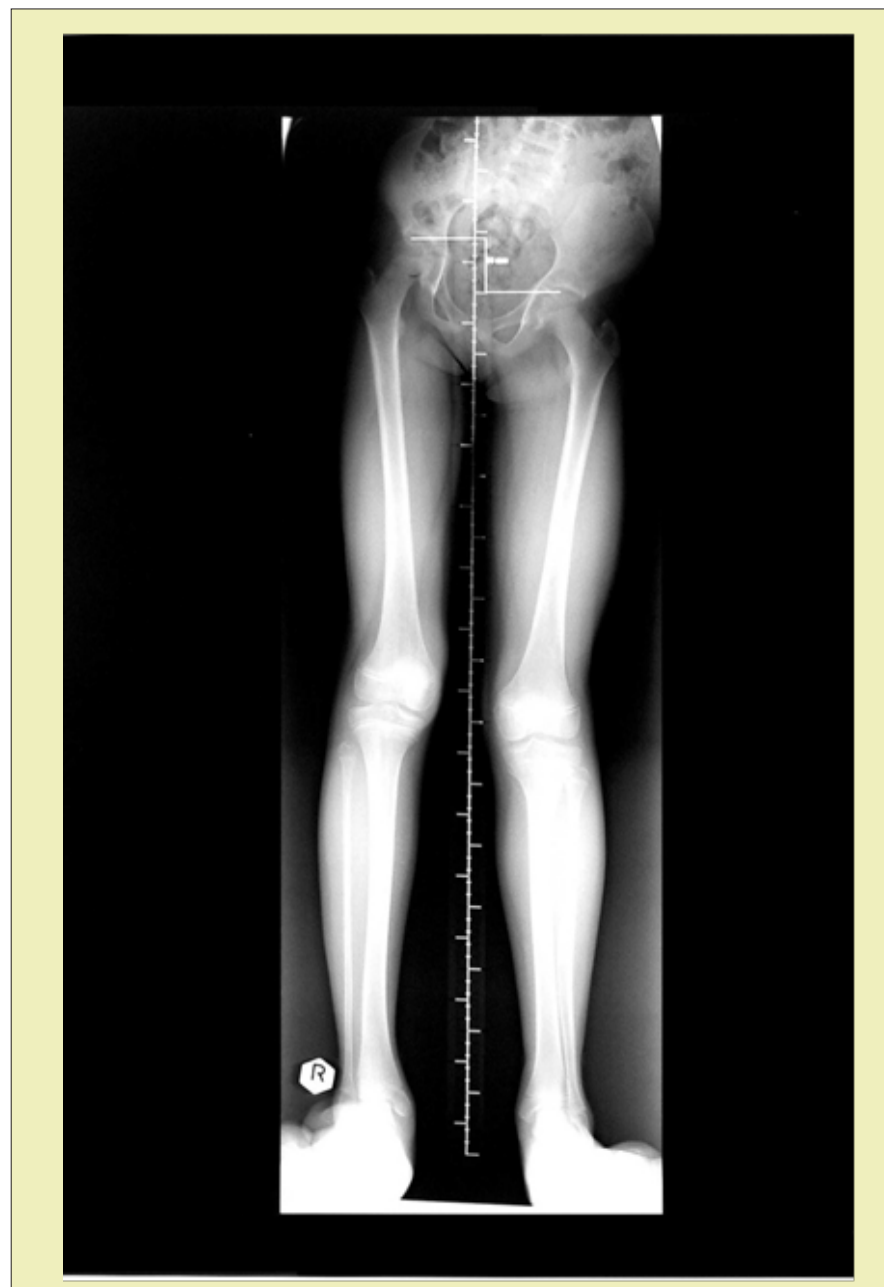

Figure 4: Shortening of the left lower limb by $4.5 \mathrm{~cm}$.

After a series of surgical corrections performed over the span of six years, we succeeded in stopping the overgrowth of digits on both hands and feet. The patient wore size 39 orthopedic shoes, and the flexibility of the corrected fingers on her hands was good. At age 12 she was, despite a shorter left leg of $4.5 \mathrm{~cm}$, (Figures 5 and 6) capable of carrying out everyday activities as well as engaging in sports such as skiing, skating, roller skating and dancing. 


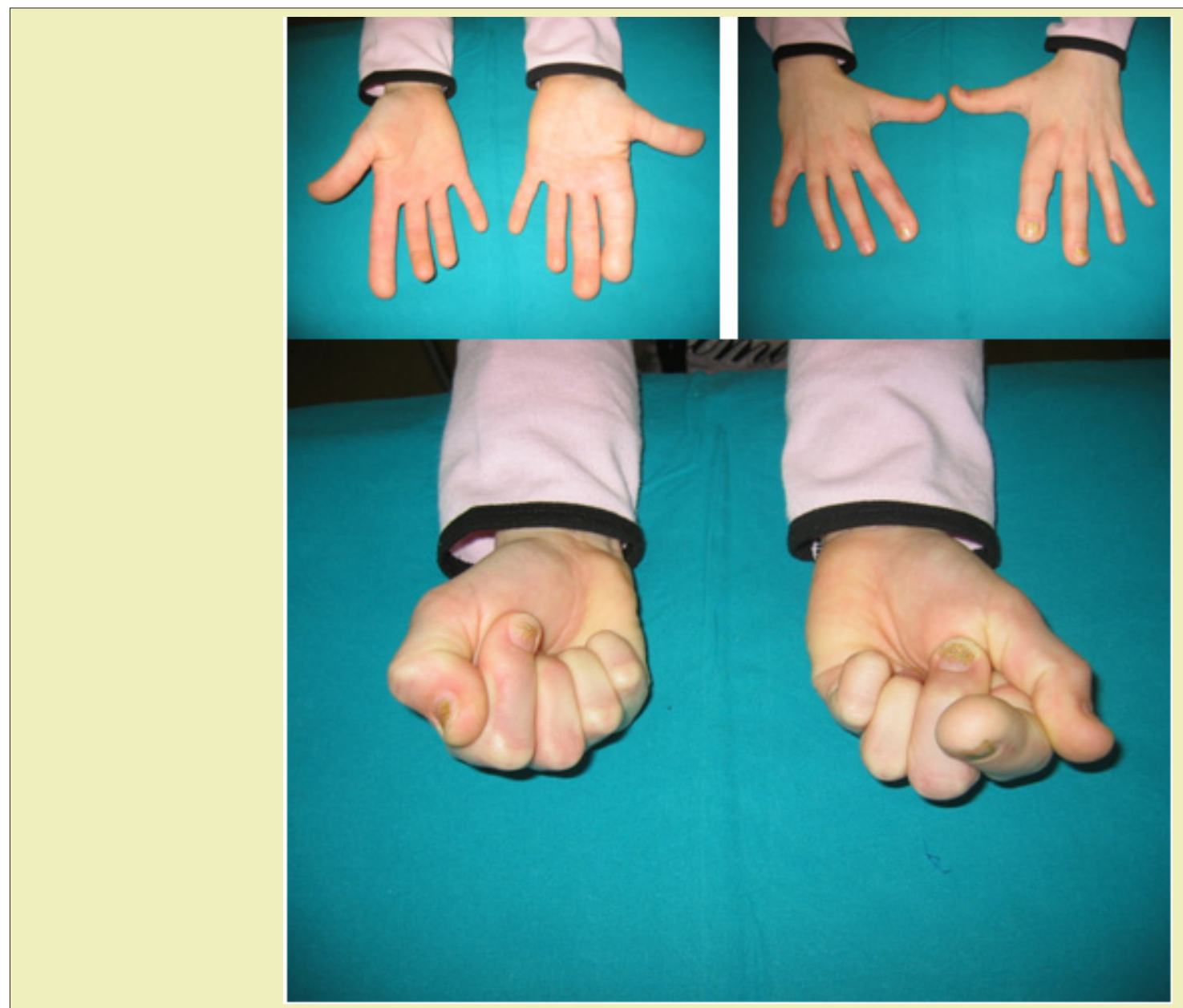

Figure 5: Good hand function preserved by multi-stage corrections of affected fingers.

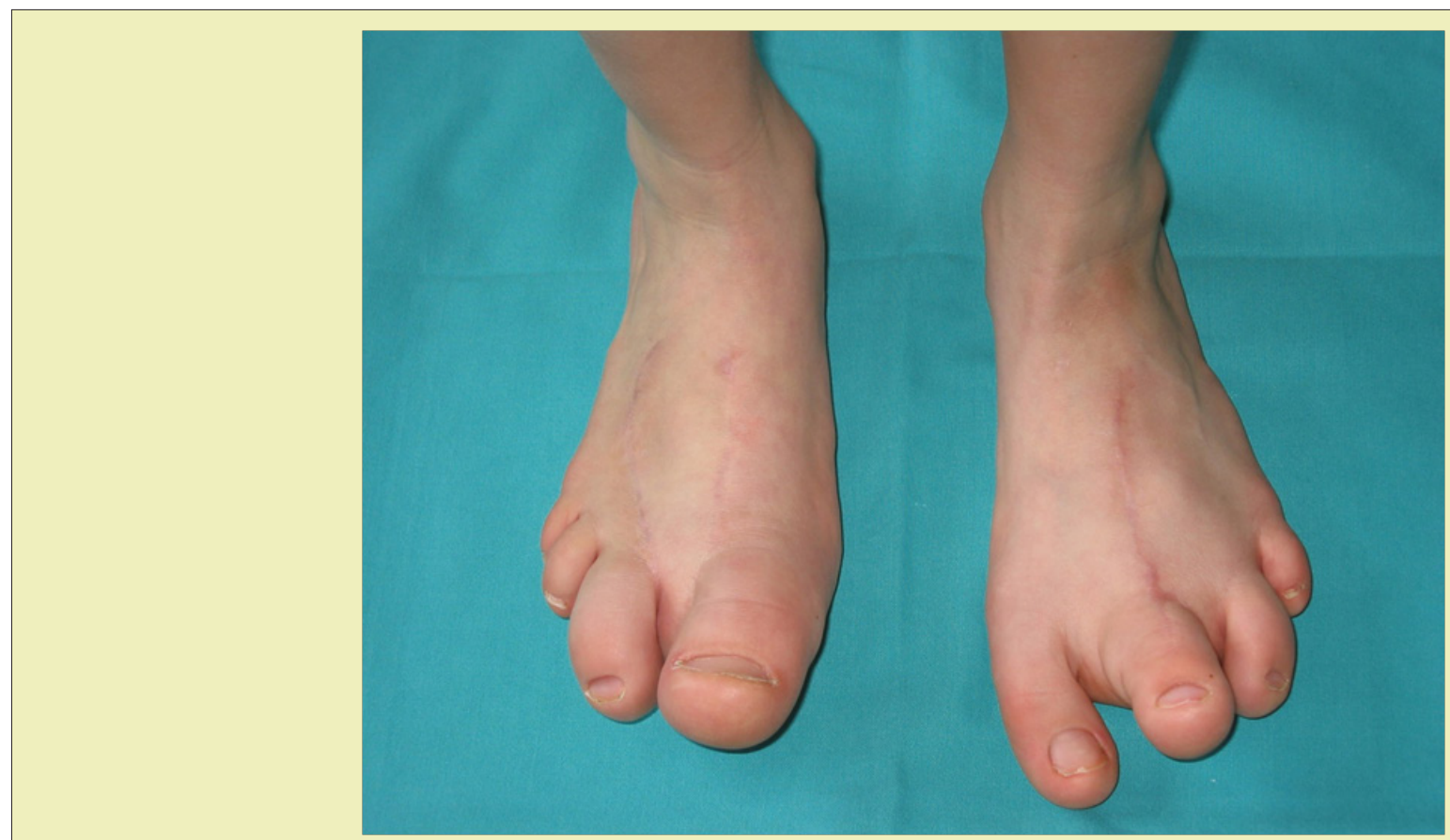

Figure 6: The growth of legs stopped at estimated adult size by the reduction of subcutaneous fat, shortening of metatarsals and toe phalanges, amputation of the third toe with related metatarsal in the left foot and of the third toe with related metatarsal in the right foot. The length discrepancy is effectively corrected by wearing orthopedic shoes. 
Since then her body development has been normal with no new pathological alterations. Today she is a student, 22 years of age and, according to her, experiences no limitations in carrying out every day and sports activities (Figures 7 and 8).
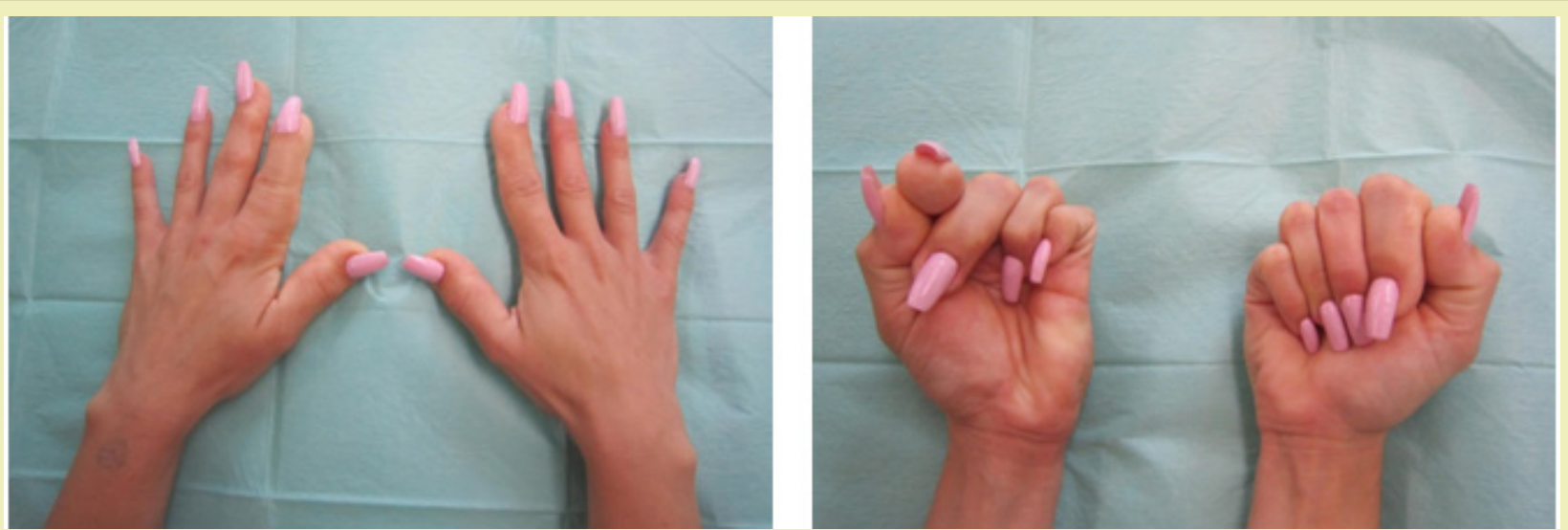

Figure 7: The finger size at present remains the same as after the completed corrections, their flexibility is good.

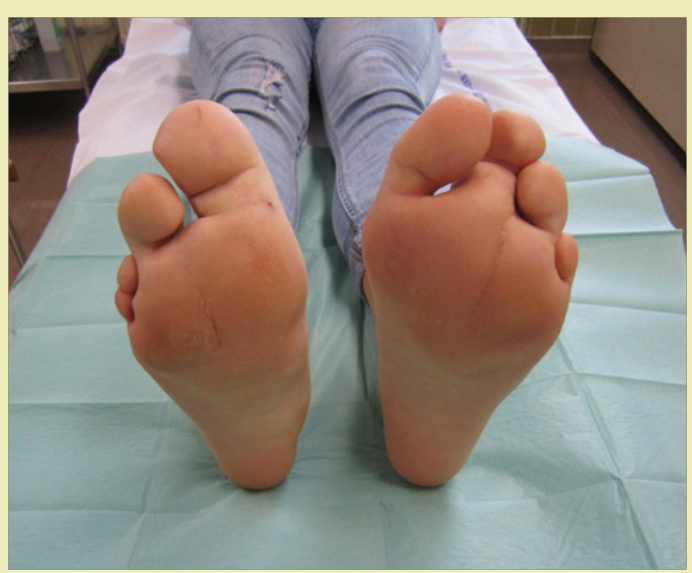

Figure 8: The feet size remains the same as after the completed corrections. After corrective subtrochanteric ostetomy the lower limb length remains the same and the patient can wear normal footwear.

\section{Discussion}

Control of cell growth depends on cell growth determinants, cell proliferation and on apoptosis or cell death. Both systemic and localized cell growth is important for the size of an individual organ, while the total cell mass is regulated by internal and external cell signals. The growth factor is of crucial importance. ${ }^{5}$

PS and PLS syndromes are rare genetic disorders. They occur sporadically as the consequence of mosaicism in somatic cells. Mosaicism refers to the presence of two or more cell types with genetic or chromosome anomalies. As a phenomenon it occurs in multi-cell organisms with variable phenotypic and developmental characteristics and in new growths. ${ }^{6}$ The exact genetic basis of PS and PLS has not been adequately explained. Godship, et al. writes about autosomnal "paradominant" inheritance with new mutations, while the most likely hypothesis relates to somatic mosaicism with a mutation of the somatic cell gene during embriogenesis. So far the biochemical, cytogentic and molecular mutations typical of both syndromes remain unknown. ${ }^{8}$ New genetic research points at the likely connections of PS and PLS with the PTEN mutations of germinative cell suppressor gene on the 10q23 chormosome. This gene slows down cell growth by regulating the activities of the lipid photastasis enzyme. ${ }^{3,9}$ Clinical manifestations vary considerably, as mutations do not follow a uniform pattern. Rather, they may occur in all germinative layers. Overgrowth may affect the skin subcutis, connective tissues, skeleton, central nervous system and individual internal organs ${ }^{10}$. Based on the analysis of cases so far, Biesecker, et al. set new, stricter criteria, dividing them into general and specific ones. The general ones include mosaic distribution of alterations, a progressive development and isolated occurrence. Specific criteria are divided into three groups of clinical changes (A, B, C) according to the type and location of growth and frequency of occurence. ${ }^{1}$ In order to confirm the PS or PLS diagnosis, all three general and/ or several specific criteria have to be met. Typical of PS are connective tissue nevi, but they are not necessarily present. They most frequently occur in the sub cutis of the feet. They typically cause cerebriform skin, are made of collagen zed connective tissue ${ }^{11}$ and are referred to as moccasin foot. Skin alterations may also occur as epidermal nevi of various sizes.

Disproportionate asymmetrical overgrowth most often occurs in the upper and lower limbs, especially in the hands, feet and/or digits, typically manifested as lengthening or enlargement of the limb. Progressive overgrowth of tissues also causes skeletal mutations and movement disorders. Cases of primary hyperostosis are rarer, while bone substance may be normal or not. ${ }^{12}$ Hyperostoses may occur in various bones, even in the ear passage. ${ }^{13-15}$ Typical alterations in the structure and morphology of blood vessels affect primarily the small blood vessels and capillaries. ${ }^{16}$ The growth of fat tissue is disproportionate. Biesecker describes both overgrowth of mature fat cells and their insufficient growth. ${ }^{9,10}$ In 1993, Cohen described the typical facial changes in PS patients: dolichocephaly, long-face syndrome, anti mongoloid slant with ptosis of the eyelids, open mouth posture and low bridge nose. ${ }^{17}$ Slavotinek, et al. proved a higher tendency to thromoembolic complications due to blood clotting disorders, which increases the riskiness of corrective surgeries. ${ }^{18}$ Overgrowth may affect the inner organs' tissue, especially 
spleen, thymus, sexual glands and ear gland. The growth may be benign, but often turns malign in patients older than 20 years ${ }^{19}$. The causes of premature death due to PS are variable. ${ }^{20}$

Except for the overgrowth of soft tissues and skeleton, no other anomalies were confirmed in our patient. Ovarian cysts and borderline inter ventricular septum of the heart do not represent a serious risk for disease progression. According to the data and literature survey, however, we need to monitor her development in order to detect any potential occurrence of anomalies or functional changes in any of her individual organs. ${ }^{21}$ Genetic studies so far have not confirmed any mutations.

\section{Conclusion}

Overgrowth syndrome manifested in excessive growth of the parts of the hands and feet present complex therapeutic challenges, especially for plastic surgeons or surgeons specializing in hand surgery. ${ }^{22}$ Orthopedic surgeons are often also involved in treatment. Recent genetic studies are of great help in classifying and determining overgrowth syndrome and, consequently, in decision-making and planning surgical procedures. The aim of reconstruction surgery is to preserve maximally normal function of the affected limb. This goal is achieved through multi-stage reconstruction, whereby we try to stop the growth of a particular part of the limb at the point where it reaches the estimated adult size. In this, we rely on the relative size of the parents. The best results are observed in the correction of skeletal deformations, while the reduction of hyperthropic subcutaneous parts are somewhat less predictable due to their frequent recurrence and are thus less successful. In feet correction we often resort to amputation. The basic principle of surgical reconstruction is to come as close as possible to the normal function and esthetic appearance of the affected limb, as this contributes to the pscychophysical health and quality of life of the patient.

\section{References}

1. Biesecker LG, Happle R, Mulliken JB, et al. Proteus sindrome: Diagnostic criteria, differential diagnosis, and patient evaluation. Am J Med Gen. 1999; 84(5): 389-395.

2. Carty MJ, Taghinia A, Upton J. Overgrowth Conditions: A diagnostic and Therapeutic Conundrum. Hand Clin. 2009; 25(2): 229-245.

3. Orloff MS, Eng C. Genetic and phenotypic heterogeneity in the PTEN hamartoma tumour syndrome. Oncogene. 2008; 27: 5387-5397.

4. Hobert JA, Eng C. PTEN hamartoma tumor syndrome: AN overview. Genetics in Med. 2009; 11(10): 687-694.

5. Houlston RS. What is known about the genetic control of tissue growth? Proteus and other localised over-growth syndromes: a multi-specialty symposium. Institute of Child Health, London 2002.
6. Turner JT, Cohen MM Jr, Biesecker LG. Reassessment of the Proteus syndrome literature: Application of diagnostic criteria to published cases. Am J Med Genet Part A. 2004; 130A(2): 111-122.

7. Goodship J, Redfearn A, Milligran D, et al. Transmission of Proteus syndrom from father to son?. J Med Genet 1991; 28(11): 781-5.

8. Waite KA, Eng C. Protean PTEN: Form and Function. Am J Med Genet. 2002; 70(4): 829-844.

9. Zhou XP, Marsh DJ, Hample H, et al. Germline and germline mosaic PTEN mutations associated with a Proteus-like syndrome of hemihypertrophy, lower limb asymetry, arteriovenous malformations and lipomatosis. Hum Molec Genet 2000; 9(5): 765-7 68.

10. Biesecker LG. The Multifaceted Challenges of Proteus Syndrom. JAMA. 2001; 285(17): 2240-2243.

11. Twede JV, Turner JT, Biesecker LG, Darling TN. Evolution of skin lesions in Proteus syndrome. J Am Acad Dermatol. 2005; 52(2): 834-838.

12. Pazzaglia UE, Giampiero B, Bonaspetti G,et al. Bone malformations in Proteus syndrome: an analysis of bone structural changes and their evolution during growth. Pediatr Radiol. 2007; 37(8): 829-835.

13. Jamis Dow CA, Turner J, Biesecker LG, et al. Radiologic manifestations of Proteus syndrome. Radiographies. 2004; 24(4): 1051-1068.

14. Becktor KB, Becktor JP, Karnes PS, et al. Craniofacial and Dental Manifestations of Proteus Syndrome: A Case Report. Cleft Palate Cranio J. 2002; 39(2): 233-245.

15. Barness EG, Cohen MM, Opitz JM. Multiple Meningeomas Craniofacial Hyperostosis and retinal Abnormalitis in Proteus Syndrome. Am J Med Genet. 2000; 93(3): 234-240.

16. Caux F, Plauchu H, Chibon F, et al. Segmental overgrowth, lipomatosis, arteriovenous malformation and epidermal nevus (SOLAMEN) syndrome is related to mosaic PTEN nullzygosity. Eu J of Hum Gen. 2007; 15(7): 767-773.

17. Cohen MM. Asymetry: Molecular, Biologic, Embryophatic, and Clinical Perspectives. Am J Med Genet. 2001; 101(4): 292-314.

18. Slavotinek AM, Vacha SJ, Peters KF, et al. Sudden death caused by pulmonary throbembolism in Proteus Syndrome. Clin Genet. 2000; 58(5): 386-3 89.

19. Gordon PL, Wilroy RS, Lasater OE, et al. Neoplasms in Proteus Syndrome. Am J Med Genet. 1995; 57(1): 74- 78.

20. Cohen MM. Couses of Premature Death in Proteus Syndrome. Am J Med Genet. 2001; 101(1): 1-3.

21. Biesecker LG, Peters KF, Darling TN, Choyke P, Hill S, et al. Clinical Differentiation Between Proteus syndrome and Hemihyperplasia: Description of a Distinct Form of Hemihyperplasia. AM J Med Genet. 1998; 79(4): 311-318.

22. Lublin M, Schwartzentruber DJ, Lukish J, Chester C, Biesecker Newman KD. Principles for the Surgical Management of Patients With Proteus Syndrome and Patients With Overgrowth: Not Meeting Proteus Criteria. J Pediatr Surg. 2002; 37(7): 1013-1020. 